\title{
A vision for the future of the ICTF
}

The International Commission on the Taxonomy of Fungi (ICTF) was established by the IUMS Division of Mycology at the XII International Microbiology Congress in Boston (MA, USA) in August 1982. At IMC5 in Vancouver in 1994, the ICTF decided that it it was appropriate for it to act as an inter-union body between IUMS and the International Union of Biological Sciences (IUBS) - the body in which the IMA is a scientific member; ICTF was accepted as an inter-union scientific member of IUBS at the IUBS General Assembly in Paris in September 1994.

The ICTF was envisioned as a taxonomic complement to the nomenclatural Committee for Fungi which is established by each six-yearly International Botanical Congress, and which is concerned with formal nomenclatural proposals. The principle objectives of the new Commission were, in contrast, to foster interest and good practice in fungal taxonomy, to provide a mechanism to foster collaborative work on critical groups, and to identify areas of concern on nomenclatural matters amongst microbiologists for debate - and where appropriate transmit those views to the Committee for Fungi.

The activities have included the production of a synopsis of changes in the International Code of Botanical Nomenclature relevant to fungi following the Sydney Congress (Hawksworth 1984), a list of genera in most need of taxonomic work (Hawksworth 1986), a Code of practice for systematic mycologists (Sigler \& Hawksworth 1987), and a series of papers drawing attention to (and explaining the reasons for) name changes in fungi of microbiological, industrial, and medical importance (Cannon 1986-90) - the short-lived name-changes series was made possible through financial support received from the IUMS Division of Mycology. The latest publication is the How to describe a new fungal species in this issue of IMA FUNGUS (Seifert \& Rossman 2010). The ICTF has also been responsible for the organization of symposia during IMA and IUMS congresses on several occasions. The rôle of the ICTF as an umbrella organization for international collaborations on different groups of fungi, normally genera, has been especially successful with subcom-

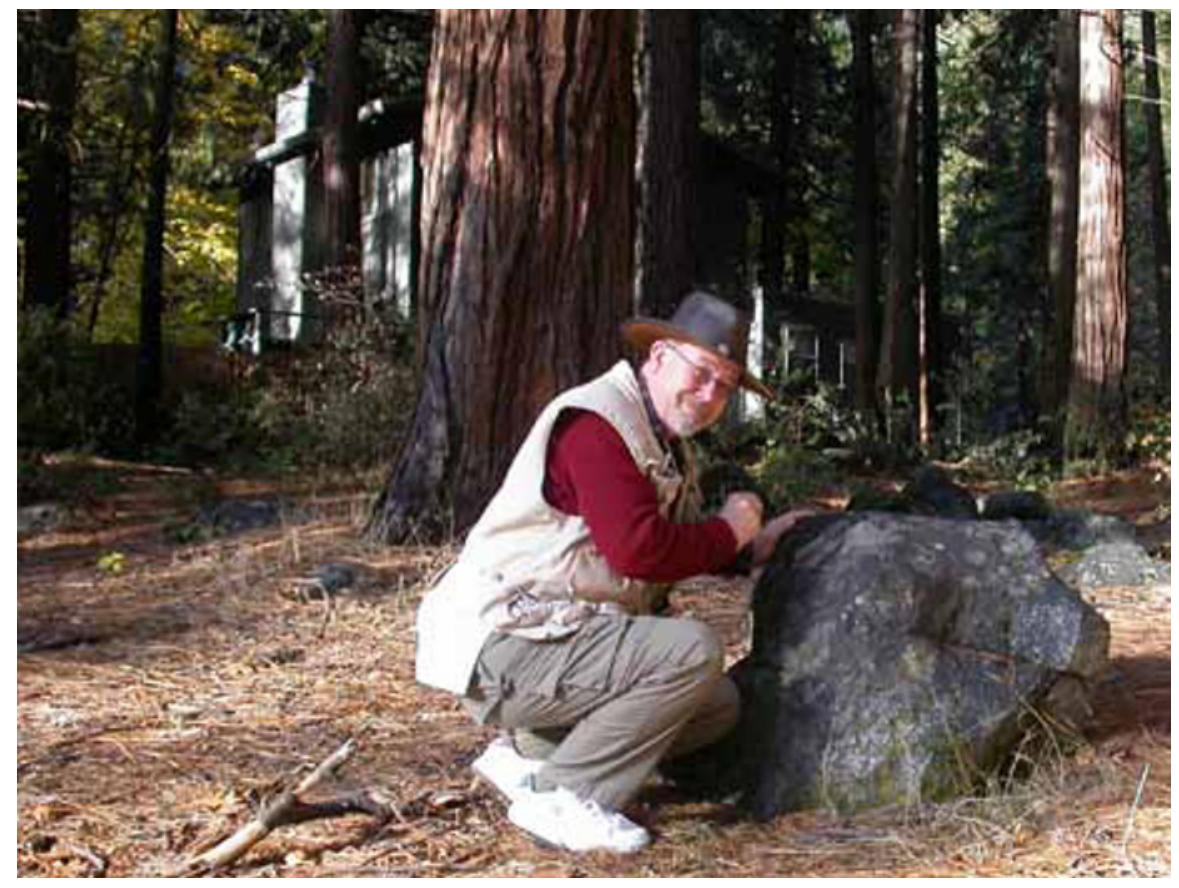

David Hawksworth searching for a lichenicolous fungus on a Xanthoparmelia in Yosemite National Park, California, 8 November 2010.

missions working on various critical groups. Most productive have been those concerned with Aspergillus and Penicillium (formed 1986; later an IUMS commission in its own right and produced a subsequently protected list of species names in current use; Pitt \& Samson 1993), Fusarium (with the International Society for Plant Pathology), and Trichoderma (formed 1989). Less active have been those concerned with Ceratocystis/Ophiostoma, and Cladosporium/ Mycosphaerella. Suggestions for subcommissions on Alternaria, Colletotrichum, and Pythium sadly never progressed. However, the new subcommission on Fungal Barcoding (formed in 2009; FunBOL) has made a promising start. A report on recent activities is included in this issue of IMA FUNGUS (Seifert \& Okada 2010).

As to the future, the ICTF is currently considering its role, and how it could or indeed should develop in the coming years. As a start to this debate, and to open this discussion to a wider mycological community than those nominated at IMC9 to consider the matter, my vision is that the ICTF should in future be involved in:

1. Overseeing existing, and being proactive in the formation of, subcommissions on a wider spectrum of fungi, includ- ing macromycetes and lichens - with a target of 10 being active by 2014 , and 20 by 2018 .

2. Providing annual summaries and explanations of the reasons for name changes in fungi of all groups which are of agricultural, ecological, environmental, industrial, or medical importance - in IMA FUNGUS and also on the IMA and IUMS Mycology Division websites.

3. Developing a series of pragmatic how-to guidelines for good practice in systematic mycology - on the lines of How to describe a fungus.

4. Developing a set of minimum standards for the description of new genera and species in particular groups - for distribution to all mycological journals.

5. Organizing one or more Nomenclature Sessions during all future IMCs - to both debate and vote on formal proposals, and also to develop acceptable solutions to controversial issues.

6. Organizing at least one symposium during all future IMCs and IUMS Division of Mycology congresses - these to be on exciting advances or controversial issues.

7. Providing inputs of views on particular nomenclatural issues to the Committee for Fungi - when requested to do so or proactively. 
8. Preparing agreed responses to International Botanical Congress Nomenclature Section meetings decisions on proposals related to mycological issues for example the voting on governance of the Code and the mandatory deposit of nomenclatural information on new taxa at the 2011 Melbourne Congress.

9. Developing a co-ordinated mycological response to the proposals for a BioCode to cover all groups of living and fossil organisms - a new draft (updated from 1997), and prepared at the request of the IUBS General Assembly held in Cape Town in 2009, is due to be released by January 2011.

10. Providing a mechanism to decide which of two or more competing generic names should be adopted for fungi with pleomorphic life-cycles - this may become necessary should proposals to move towards a single scientific name for each fungal species be formally adopted.

11. Preparing reports of its activities annually to the IMA Executive Committee (for inclusion in IMA FUNGUS), and to each IMC, IUBS General Assembly, and IUMS Mycology Division congress and making proposals for financial support whenever the opportunity arises.
12. Advising the IMA Executive Committee on all matters concerned with the taxonomy of fungi - both at the request of the Executive Committee and proactively.

13. Extending the number of ICTF members from 15 to 30 - to provide representation of a wider spectrum of fungal groups and with members delegated to be responsible for the furtherance of particular activities.

This list is certainly daunting, and made without prejudice to the final decisions of the group of ICTF members mandated to address this issue, but 13 has always been a lucky number for me. In essence, the points represents a personal vision of the ICFT becoming the key over-arching body responsible for the furtherance of all aspects of fungal systematics that are not within the remit of the Committee for Fungi. To fully achieve this vision will take many years, but some points could be progressed in the short term. In this, the $13^{\text {th }}$ point is of critical importance. In my opinion, the principle reason for the ICTF not to have yet achieved its potential and realized its original vision has been that its officers and members have tended to be senior mycologists already over-committed with heavy personal and institutional duties. In consequence they, and not least me, have not been able to accord ICTF matters the priority they require. I personally feel guilty that I had not been able to do so much more during my term as ICTF Chair.

The future of the ICTF, and the election of new members and officers, are scheduled to take place during the One Fungus: One Name (1F: 1N) in Amsterdam on 19-21 April 2011. Do not be backward in coming forward to express your own views on the vision presented here, however critical or controversial you think they may be, to make new suggestions, or to volunteer to join or work in a rejuvenated Commission (or one of its less active or proposed Subcommissions). Responses should be sent to the current Chair (Keith Seifert; keith. seifert@agr.gc.ca) and Secretary (Gen Okada; okada@jcm.riken.jp) by 28 February 2011 - in order to inform the working group established at IMC9 to develop its report on the future of the ICTF for the April meeting.

\section{David L Hawksworth}

ICTF Chair 1982-2000

(d.hawksworth@nhm.ac.uk)

Cannon PF (1986-90) International Commission on the Taxonomy of Fungi (ICTF): Name changes in fungi of microbiological, industrial and medical importance.

Parts 1-4. Microbiological Sciences 3: 168-171 (1986), 285-287 (1986), 5: 23-26 (1988); Mycopathologia 111: 75-83.

Hawksworth DL (1984) Recent changes in the international rules affecting the nomenclature of fungi. Microbiological Sciences 1: 18-21.

Hawksworth DL (1986) Fungal genera in urgent need of taxonomic work. Microbiological Sciences 3: 58.

Pitt JI, Samson RA (1993) Species names in current use in the Trichocomaceae (Fungi, Eurotiales). Regnum Vegetabile 128: 14-57.

Seifert KA, Okada G (2010) International Commission on the Taxonomy of Fungi (ICTF). IMA Fungus 1: (11)-(12).

Seifert KA, Rossman AY (2010) How to describe a new fungal species. IMA Fungus 1: 109-116.

Sigler L, Hawksworth DL (1987) International Commission on the taxonomy of Fungi (ICTF): Code of practice for systematic mycologists. Microbiological Sciences 4: 83-86; Mycopathologia 99: 3-7; The Mycologist 21: 101-105; Acta Mycologica Sinica 8: 154-159 (1989). 